Sharif University of Technology
Scientia Iranica
Transactions E: Industrial Engineering
hCIttp://scientiairanica.sharif.edu
IRAN ICA

\title{
A dual model for selecting technology and technology transfer method using a combination of the Best-Worst Method (BWM) and goal programing
}

\author{
S. Amirghodsi ${ }^{\mathrm{a}}$, A. Bonyadi Naeini ${ }^{\mathrm{a}, *}$, and A. Makui ${ }^{\mathrm{b}}$ \\ a. Department of Management and Business Engineering, School of Progress Engineering, Iran University of Science and \\ Technology, Tehran, Iran. \\ b. School of Industrial Engineering, Iran University of Science and Technology, Tehran, Iran.
}

Received 7 July 2019; received in revised form 2 July 2020; accepted 18 October 2020

\section{KEYWORDS \\ Supplier selection; Technology selection; Best-worst method; Goal programming; Gray analytical network process.}

\begin{abstract}
As a vital criterion for the supply chain, supplier selection has significant effects on the chain structure. Three important factors contribute to the selection process: product/technology selection, technology/product transfer method selection, and supplier selection. Followed by defining the influential criteria for these factors, the current study employed Best-Worst Method (BWM) to measure the weights. Next, the three factors were incorporated into Goal Programming (GP) to minimize the cost and failure risk and maximize the service and environmental compliance levels. The results of the GP demonstrated the level of demand allocation to the supplier(s). Further, Gray Analytical Network Process (GANP) was used as the best decision-making method and over the past four years, BWM was applied in decision-making processes. Therefore, the GANP method was used to measure the weights of criteria. These weights were also incorporated into GP for comparison with the proposed combination. The results confirmed the superiority of BWM-GP over GANP-GP due to its ability to reduce both cost and failure, in addition to the increased level of service and environmental compliance.
\end{abstract}

(C) 2022 Sharif University of Technology. All rights reserved.

\section{Introduction}

One of the significant factors contributing to the economic growth is the productivity of production resources which is influenced by several criteria such as knowledge and Technology Transfer (TT) [1]. New technologies have introduced more effective ways to evaluate new aspects of human activities. In other

\footnotetext{
*. Corresponding author. Tel.: +9821 73228056;

Fax: +9821 73021621

E-mail addresses: amirghodsi@vu.iust.ac.ir (S. Amirghodsi); bonyadi@iust.ac.ir (A. Bonyadi Naeini); amakui@iust.ac.ir (A. Makui)
}

doi: $10.24200 /$ sci.2020.53925.3511 words, application of new technologies can considerably enhance the quality of services, improve the efficiency, reduce the required time to distribute new products to the market, and satisfy inexhaustible needs [2]. Developing countries have strengthened their technological foundations by transferring technologies from developed countries. In addition, they have improved their academic and research facilities by creating appropriate economic infrastructure [3]. However, given that few countries are self-sufficient in terms of technological demands, TT has gained greater significance in bridging the technological gap between the developing and developed countries.

Different methods can facilitate the TT process depending on the position of the technology receiver 
and donor [4,5]. Any business enterprise should take into account the technology assessment and transfer methods implemented at specific intervals. Different studies have been conducted around the world including a study by Klintenberg et al. [6] who examined the success factors for TT from developed to developing countries.

The current research aimed to propose a novel and efficient method of TT in two simultaneous steps of technology selection and TT method selection. However, to the best of the authors' knowledge, there are a limited number of studies examining these two steps of TT simultaneously. The proposed model in this study was developed to control uncertainties in different situations, which have been neglected in previous studies. In this regard, Best-Worst Method (BWM) was considered as the best method for measuring the weights of effective criteria owing to its ability to yield optimal results. In addition, the weights obtained from Gray Analytical Network Process (GANP) were compared with those from the BWM, and they are used as a variable coefficient in the mathematical modeling.

The rest of this paper is structured as follows. Section 2 describes the research background; Section 3 provides a description of BWM, GANP, and mathematical modeling; Section 4 presents the results of a case study and data analysis; and Section 5 presents the conclusions.

\section{Literature review}

A variety of decision-making methods have been employed to date for TT selection. A previous study employed Analytic Network Process (ANP) method to confirm the priority of TT methods in the oil drilling industry [7]. In addition, it incorporated DecisionMaking Trial and Evaluation Laboratory (DEMATEL) into the ANP to select the light-emitting diodes of a building [8]. Moreover, it used the ANP method to determine a suitable technology for wastewater treatment in Malaysia [9]. Aliakbari Nouri et al. [10] employed a hybrid Multi-Criteria Decision-Making (MCDM) approach based on the fuzzy Technique for Order Preference by Similarity to Ideal Situation (TOPSIS) and fuzzy ANP for technology selection. In another study, Lee et al. used the fuzzy ANP method and combined it with the fuzzy Delphi method to select the best supplier in the transistor industry [11]. Dou et al. [12] developed a GANP-based model to examine green supplier development programs. Tuzkaya and Yolver [13] utilized an integrated GANP method to measure the weights of criteria and select a research and development project. They also ranked the projects based on Gray Relational Analysis (GRA).

TOPSIS is another MCDM method that is used along with fuzzy numbers to select the best source of technology in different industries including medical equipment [14-16]. In this regard, Sharawat and Dubey [17] employed the TOPSIS method to rank the criteria and select the technologies concerning both health and treatment aspects. Kumar et al. [18] considered Analytical Hierarchy Process (AHP), a simple and effective MCDM method, to determine the influential factors in the TT process and calculate the correlation coefficients. A few years later, Hu et al. [19] attempted to select an appropriate technology for wastewater treatment plants by adding fuzzy numbers and incorporating the preferential ranking technique to the AHP. Farshidi et al. [20] used the AHP method for designing a decision support system and selecting a software technology. Mokhtarzadeh et al. [21] took into account the structural hierarchy process to identify the influential criteria in technology selection in the information technology industry. Rahimi et al. [22] employed the AHP technique to rank the technologies and select an appropriate location for a hospital.

On the contrary, Amirghodsi et al. [23] applied a hybrid Delphi-DEMATEL-ELECTRE method to the gray numbers to rank technology providers. Sahin and Yip [24] conducted a case study to improve the structural hierarchy method of TT in the transportation industry, followed by describing the Gaussian fuzzy analytic hierarchy process. Their results confirmed that the proposed model was appropriate for the selection of proper transportation technology. In another study, Mardani et al. [25] used the Data Envelopment Analysis (DEA) to assess energy efficiency. Goker and Karsak [26] attempted to improve the criterion weights using the DEA technique.

Ren [27] employed a general MCDM model to classify ballast water treatment technologies. They combined the internal consistency, weighted objectives, and BWM methods to calculate the weights. Van de Kaa et al. [28] utilized the BWM to calculate the relative importance (weight) of the evaluation criteria in Netherlands. Then, they calculated the weights of the criteria to rank the best biomass thermochemical conversion technologies. Rezaei et al. [29] employed both BWM and Service Quality (SERVQUAL) methods to evaluate the quality of luggage loading systems. In their study, while the SERVQUAL took into account the intangible performance aspects, the BWM determined the weights of the service quality criteria. Rezaei et al. [30] identified the most qualified supplier in the edible oil industry based on the BWM. Setyono and Sarno [31] used BWM for weighing the criteria under study, which were formerly examined and oriented to the business objectives of the company. They also compared Multi-Objective Optimization on the basis of Ratio Analysis (MOORA) and Complex Proportional Assessment (COPRAS) approaches to assess the supplier. 
In order to rank the hydrogen production technologies with data uncertainties, $\mathrm{Xu}$ et al. [32] introduced a novel MCDM framework by combining Interval BWM (IBWM) method, Interval Best-Worst Projection (IBWP) method, and Interval Entropy Technique (IET). Jafarzadeh Ghoushchi et al. [33], in a case study in the oilseed industry, addressed sustainable supplier selection. For determining the weights of the supplier selection criteria, they used Fuzzy Best-Worst (FBWM) method. Next, they ranked the suppliers using a piecewise linear function. Hendalianpour et al. [34] used Interval-Valued Fuzzy-Rough Number (IVFRN)-BWM method for ranking the suppliers. Overall, different MCDM methods namely the DEMATEL, ANP, AHP, TOPSIS, and BWM were frequently used in different studies. However, BWM was found to yield more desirable results than those from other methods.

Lee and Kim [35] developed the ANP and zeroone Goal Programming (GP) for interdependent information system project selection. A few years later, Yurdaklu [36] presented a combined AHP and GP model to select the computer-integrated manufacturing technologies. Feng et al. [37] used both linear mathematical model and MCDM approach simultaneously to select and evaluate the suppliers. Kannan et al. [38] employed multi-criteria hybrid approaches to rank the suppliers. They measured the weights of criteria in their study and ranked them based on the fuzzy AHP method. Followed by weighing the selected criteria, they took into account the fuzzy multi-objective linear programming to define the optimal supplier order. $\mathrm{Li}$ and Wan [39] proposed a mathematical model to select the best supplier and adopted a fuzzy GP approach to assess the predetermined criteria weights. Hamurcu and Eren [40] incorporated the weights obtained from the AHP into a GP model to identify the best alternative electric automobile technology. Lin et al. [41] recently devised a new decision-making framework to solve the decision-making problem of selecting biorefineries under uncertainties.

Vahidi et al. [42] established a randomized, probabilistic, two-step programming model of supplier selection to maximize the stability, increase supplier flexibility, and minimize the total cost. Sarkar et al. [43] integrated the Multi-Attribute Decision-Making (MADM) approach and mathematical programming, along with quantitative and qualitative criteria, combined fuzzy ANP-based DEMATEL method, fuzzy TOPSIS method, and Multi-Segment Goal Programming (MSGP) for supplier selection. Hendalianpour et al. [44] used zero-one mixed-integer programming where the objective function succeeded in minimizing the cost of the distribution chain and enhancing the customer satisfaction.

Previous studies have proposed different criteria concerning the technology selection and transfer. For instance, Mazdeh et al. [45] considered the influential factors in TT including technology localization, complexity, willingness to learn, organizational distance, mutual trust, and learning culture. In addition, Kharat et al. [46] addressed the criteria of purchase and consumption costs, environmental compatibility, efficiency, technological reliability, expertise requirements, and public acceptance. Moreover, Montazeri and Najjartabar-Bisheh [47] described the criteria for technology localization, benefits of technology, and risks of replacing the existing technology with a new one.

A more precise review of the literature reveals that researchers have jointly used many evaluation criteria to assess appropriate technologies and different TT methods, indicating the close link between these two stages of the TT process. On the contrary, according to the literature review, the uncertainty aspect, as an inseparable aspect of technology selection and transfer, has been less explored in the previous studies, especially in the case of solving this problem based on gray numbers. In addition, none of the existing models simultaneously addressed the selection of technology/technology provider and TT method, and only one of these two steps is appraised in the TT process.

The present study first attempted to examine, develop, define, and rank the criteria to select the technology, supplier, and TT method. Next, by adopting a combined decision-making method, it proposed a systematic and understandable model to resolve the problem of selecting technology and TT method simultaneously to meet the requirements of different industries and organizations, especially the petroleum industry.

\section{Methodology}

The model proposed in this study consists of two main parts, namely the BWM and GP. As mentioned earlier, while the BWM method is used to weigh the criteria, multi-objective linear GP is used to determine the technology suppliers as well as the extent of order allocation. The steps of this study are elaborated in the following:

- Extracting the important criteria to select the technology, technology supplier, and TT method accomplished using an expert panel (decision-makers) who used different sources to prepare a list based on the organization's goals, requirements, and other influential factors;

- Using the BWM approach to prioritize and incorporate the weights of criteria already extracted in the previous step; 
- Feeding the outputs of the previous step as the inputs of the GP to obtain optimal results for selecting the suppliers and determining their order allocations.

Figure 1 displays the conceptual map of this study with the aim of proposing a novel integrated model for the supplier selection problem based on the BWM and GP to find reliable solutions under uncertain circumstances.

As presented in Figure 1, the extracted criteria were prioritized and weighed based on the priority matrix and BWM method. This process was repeated with the GANP method, and the obtained results were compared with the BWM results. At the end of this process, each group of suppliers, technologies, and TT methods was weighed. Finally, the results of supplier selection and amount of allocation were determined by transferring the obtained weights from each method separately to the GP model. A combination of the MCDM and GP methods was used in the proposed model. While the BMW method was considered the main decision-making model, the GANP decision- making approach was used for comparison. The three stages given in Figure 1 will be described in the following sections in detail.

\section{Stage 1: Criteria extraction}

Followed by conducting a comprehensive review of the literature and open interviews with experts, a complete set of criteria that affected the selection of technology, technology supplier, and TT method was determined. In addition, in this step, the TT methods, main suppliers of drill bits in the oil industry, and existing technologies for producing the drill bits were specified. The snowball sampling method was also employed to select the experts. At the beginning of the study, the interviewees were asked to introduce the potential experts. The experts were chosen among managers and experts of the drill goods supply and purchase department of the Iranian Central Oil Fields Company. The selected experts then cooperated with the authors in all steps of the study (e.g., decision matrix analysis). The demographic characteristics of the interviewed experts are presented in Table 1.

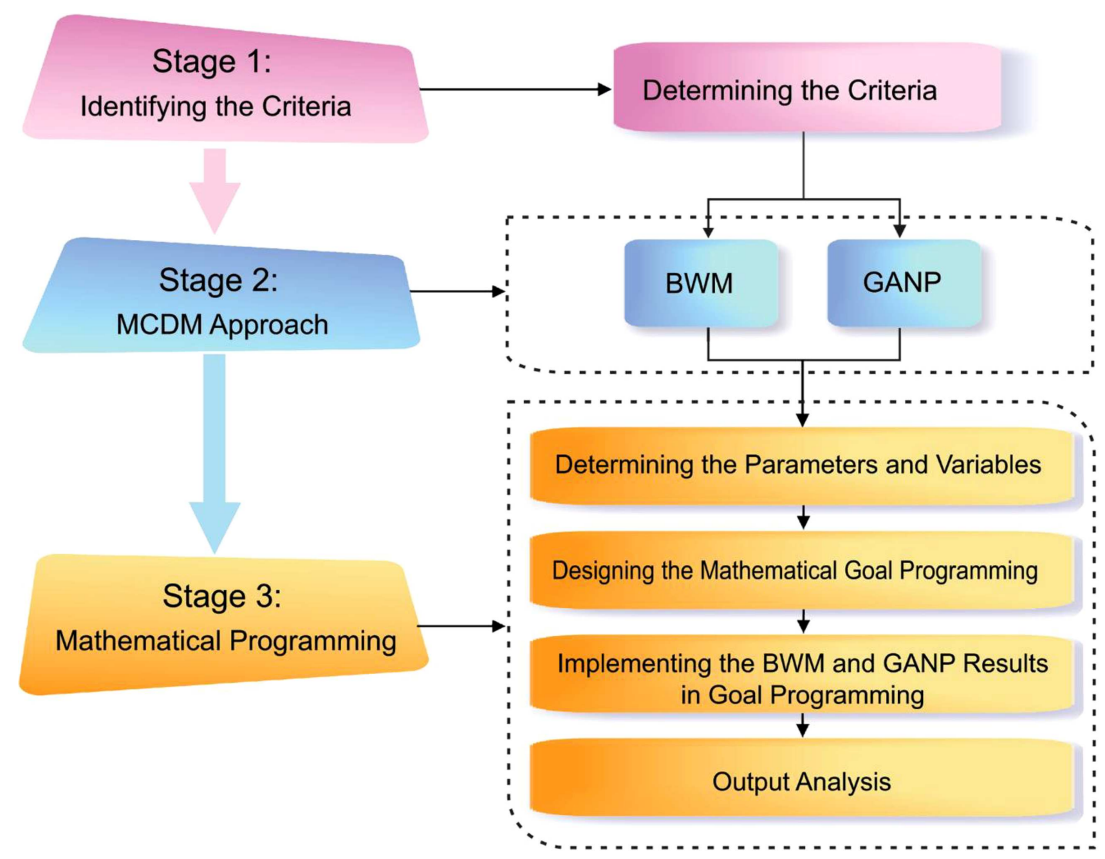

Figure 1. The conceptual model of the study.

Table 1. The demographic characteristics of the experts.

\begin{tabular}{|c|c|c|c|c|c|c|c|c|c|c|}
\hline \multicolumn{2}{|c|}{ Gender } & \multicolumn{3}{|c|}{$\begin{array}{c}\text { Educational } \\
\text { level }\end{array}$} & \multicolumn{2}{|c|}{$\begin{array}{l}\text { Work experience } \\
\text { in the building } \\
\text { industry (years) }\end{array}$} & \multicolumn{4}{|c|}{ Age (years) } \\
\hline Male & Female & Bachelor's degree & Master's degree & $\mathrm{PhD}$ & $10-20$ & $>21$ & $30-40$ & $41-50$ & $51-60$ & $>61$ \\
\hline 15 & 0 & 5 & 7 & 3 & 4 & 11 & 2 & 4 & 6 & 3 \\
\hline $100 \%$ & $0 \%$ & $33.3 \%$ & $46.6 \%$ & $20 \%$ & $26.7 \%$ & $73.3 \%$ & $13.3 \%$ & $26.7 \%$ & $40 \%$ & $20 \%$ \\
\hline
\end{tabular}




\section{Stage 2: MCDM approach}

This section discusses the two main methods used in the present study in detail. The BWM method is used as the main computing method while the GANP method is used for comparison.

\section{A. BWM method}

BWM is the newest MCDM method. Compared to other MCDM models, it enjoys several advantages such as less need for comparison and higher reliability, to name a few [48]. For example, AHP is the most widely used MCDM method that requires $(n(n-1)) / 2$ comparisons, while the BWM method requires $(2 n-3)$ comparisons [49]. Figure 2 shows the steps of this method $[30,48,50]$.

In the first step, the effective criteria in the decision-making process are identified. These criteria are assumed to be $\left\{c_{1}, c_{2}, \ldots, c_{n}\right\}$.

In the second step, the most (best) and the least important (worst) criteria are determined. Next, the superiority of the best criterion over the others is confirmed. The best-to-other vector is as follows:

$$
A_{B}=\left(a_{B 1}, a_{B 2}, \ldots, a_{B n}\right) \text {. }
$$

In this vector, $a_{B j}$ represents the preference of the best criterion $B$ over criterion $j\left(a_{B B}=1\right)$.

In the fourth step, the inferiority of the worst criterion to all other criteria is shown. The othersto-worst vector is as follows:

$$
A_{W}=\left(a_{1 W}, a_{2 W}, \ldots, a_{n W}\right)^{T} .
$$

In this vector, $a_{j W}$ represents the superiority of the criterion $j$ over the worst criterion $W\left(a_{W W}=1\right)$.

In the fifth step, the optimal weights $\left(w_{1}^{*}, w_{2}^{*}\right.$, $\left.\ldots, w_{n}^{*}\right)$ are calculated through Eq. (3). To reach the optimal weights, the maximum absolute differences $\left|\frac{w_{B}}{w_{j}}-a_{B j}\right|$ and $\left|\frac{w_{j}}{w_{W}}-a_{j W}\right|$ should be minimized for all $j$ 's:

$$
\min \max _{j}\left\{\left|\frac{w_{B}}{w_{j}}-a_{B j}\right|,\left|\frac{w_{j}}{w_{W}}-a_{j W}\right|\right\}
$$

s.t.

$$
\begin{aligned}
& \sum_{j} w_{j}=1 \\
& w_{j} \geq 0 \text { for all } j .
\end{aligned}
$$

The min-max model in Eq. (3) is used to solve the problem below:

$$
\min \xi .
$$

s.t.

$$
\begin{aligned}
& \left|\frac{w_{B}}{w_{j}}-a_{B j}\right| \leq \xi, \text { for all } j \\
& \left|\frac{w_{j}}{w_{W}}-a_{j W}\right| \leq \xi, \text { for all } j \\
& \sum_{j} w_{j}=1 \\
& w_{j} \geq 0, \text { for all } j .
\end{aligned}
$$

The optimal weights $\left(w_{1}^{*}, w_{2}^{*}, \ldots, w_{n}^{*}\right)$ and $\xi^{*}$ were measured in the abovementioned problem where $\xi^{*}$ represents the comparison consistency. A larger $\xi^{*}$ is associated with the higher consistency ratio and lower reliability of comparisons. In other words, reliability is greater when $\xi^{*}$ is closer to zero. Overall, when $a_{B j} \times a_{j W}=a_{B W}$, a consistent comparison can be made for all $j$ 's. In this regard, Rezaei (2015) proposed a Consistency Index (CI) using the maximum possible $\xi(\max \xi)$ for $a_{B W} \in\{1,2, \ldots, 9\}$, as presented in Table 2. According to the index given in Table 2, Eq. (5) is used to measure the consistency ratio $\in[0,1]$ [48]:

$$
\text { Consistency Ratio }=\frac{\xi^{*}}{\text { Consistency Index }} .
$$

It should be noted that for a not fully consistent problem $\left(\xi^{*}>0\right)$ with more than three influencing criteria, like the one arose here, there can be multiple optimal solutions. In this regard, the optimal weight

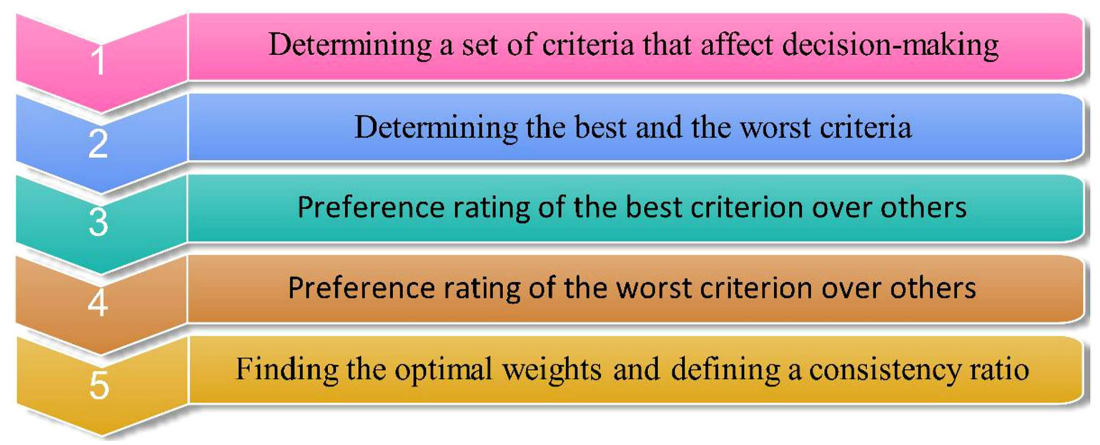

Figure 2. The BWM procedure. 
Table 2. The Consistency Index (CI) [48].

\begin{tabular}{cccccccccc}
\hline $\boldsymbol{a}_{\boldsymbol{B} W}$ & 1 & 2 & 3 & 4 & 5 & 6 & 7 & 8 & 9 \\
$\mathbf{C I}(\max \boldsymbol{\xi})$ & 0.00 & 0.44 & 1.00 & 1.63 & 2.30 & 3.00 & 3.73 & 4.47 & 5.23 \\
\hline
\end{tabular}

of each criterion is regarded as an interval. The lower and upper bounds of the weight of each criterion can be calculated through Eqs. (6) and (7). In addition, the center of each interval is considered as the weight of the criterion [51].

$\min W_{j}$

s.t.

$\left|\frac{w_{B}}{w_{j}}-a_{B j}\right| \leq \xi^{*}$, for all $j$

$\left|\frac{w_{j}}{w_{W}}-a_{j W}\right| \leq \xi^{*}$, for all $j$

$\sum_{j} w_{j}=1$

$w_{j} \geq 0$, for all $j^{\prime} \mathrm{s}$,

$\max W_{j}$

s.t.

$\left|\frac{w_{B}}{w_{j}}-a_{B j}\right| \leq \xi^{*}$, for all $j$

$\left|\frac{w_{j}}{w_{W}}-a_{j W}\right| \leq \xi^{*}$, for all $j$

$\sum_{j} w_{j}=1$

$w_{j} \geq 0$, for all $j^{\prime} \mathrm{s}$.

\section{B. GANP method}

The ANP method, used as the basis of our comparisons, is derived from the AHP method. This method can model the correlations and feedback between different decision-making elements and integrate all internal effects in the decision-making process for computations [52]. Compared to simple scoring methods, ANP presents a more robust solution with no need for complex mathematical modeling or computations $[12,53]$. This method is proved to be distinct and superior to other decision-making processes. We also used the gray system theory to include incomplete and uncertain information. Of note, the gray numbers were used in the GANP method. Despite the similarity of gray and fuzzy numbers, while the exact value of the gray numbers is still unknown, the span containing that number is clear. A fuzzy number is defined as a span, and the exact values of its left and right wings are unknown which follow a membership function [54].

\section{B.1. Gray system theory}

In case of incomplete or indeterminate information, the gray system theory is used in system analysis, modeling, data processing, and decision-making to assess the outcomes $[12,23,55]$. In addition, the gray aggregation method was employed in this study [56]. In the following equation, $x$ represents a closed and bound set of real numbers, and $\otimes x$ (a gray number) is an interval with definite upper and lower limits but indefinite distribution information for $x$ [57]:

$$
\otimes x=[\underline{\otimes} x, \bar{\otimes} x]=\left[x^{\prime} \in x \mid \underline{\otimes x} \leq x^{\prime} \leq \bar{\otimes} x\right],
$$

where $\underline{\otimes} x$ and $\bar{\otimes} x$ denote the lower and upper limits of $\otimes x$, respectively. Some basic gray number mathematical operations are presented below:

$$
\begin{gathered}
\otimes x_{1}+\otimes x_{2}=\left[\underline{x}_{1}+\underline{x}_{2}, \bar{x}_{1}+\bar{x}_{2}\right], \\
\otimes x_{1}+\otimes x_{2}=\left[\underline{x}_{1}+\bar{x}_{2}, \bar{x}_{1}+\underline{x}_{2}\right], \\
\otimes x_{1} \times \otimes x_{2}=\left[\min \left(\underline{x}_{1} \underline{x}_{2}, \underline{x}_{1} \bar{x}_{2}, \bar{x}_{1} \underline{x}_{2}, \bar{x}_{1} \bar{x}_{2}\right),\right. \\
\left.\max \left(\underline{x}_{1} \underline{x}_{2}, \underline{x}_{1} \bar{x}_{2}, \bar{x}_{1} \underline{x}_{2}, \bar{x}_{1} \bar{x}_{2}\right)\right], \\
\otimes x_{1} \div \otimes x_{2}=\left[\underline{x}_{1}, \bar{x}_{1}\right] \times\left[\frac{1}{\underline{x}_{2}}, \frac{1}{\bar{x}_{2}}\right] .
\end{gathered}
$$

The gray aggregation method, also known as a variation of the Converting Fuzzy data into Crisp Scores (CFCS) defuzzification method, was used to calculate the crisp values in a gray environment [56]. The gray number $\otimes x_{i j}^{k}$ was applied to the decision-maker $k$ in order to assess the superiority of supplier $i$ in TT method $j$. The decision-maker $k$ took into consideration the lower and upper gray values, i.e., $\underline{Q} x_{i j}^{k}$ and $\bar{\otimes} x_{i j}^{k}$, to estimate the relationship between supplier $i$ and TT method $j$ :

$$
\underline{\otimes} x_{i j}^{k}=\left[\underline{\otimes} x_{i j}^{k}, \bar{\otimes} x_{i j}^{k}\right] \text {. }
$$

There are three steps in the modified-CFCS method: 
Step 1: Normalization:

$$
\begin{aligned}
& \widetilde{\otimes} \widetilde{x_{i j}^{k}}=\left[\underline{\otimes} x_{i j}^{k}-\min _{j} \underline{\otimes} x_{i j}^{k}\right] / \Delta_{\min }^{\max }, \\
& \widetilde{\otimes} \widetilde{x_{i j}^{k}}=\left[\bar{\otimes} x_{i j}^{k}-\min _{j} \bar{\otimes} x_{i j}^{k}\right] / \Delta_{\min }^{\max },
\end{aligned}
$$

where:

$$
\Delta_{\min }^{\max }=\max _{j} \bar{\otimes} x_{i j}^{k}-\min _{j} \underline{\otimes} x_{i j}^{k} .
$$

Step 2: Calculation of the total normalized crisp value:

$$
Y_{i j}^{k}=\frac{\left(\underline{\otimes} \widetilde{x_{i j}^{k}}\left(1-\underline{\otimes} \widetilde{x_{i j}^{k}}\right)+\left(\bar{\otimes} \widetilde{x_{i j}^{k}} \times \bar{\otimes} \widetilde{x_{i j}^{k}}\right)\right)}{\left(1-\underline{\otimes} \widetilde{x_{i j}^{k}}+\underline{\otimes} \widetilde{x_{i j}^{k}}\right)},
$$

Step 3: Calculation of crisp values:

$$
Z_{i j}^{k}=\min _{j} \underline{\otimes} x_{i j}^{k}+Y_{i j}^{k} \Delta_{\min }^{\max } .
$$

\section{B.2. ANP}

The ANP method is defined as follows:

Step 1: Constructing a decision network. To construct this network, it is required to review previous studies and consult with the decision-makers. Some methods such as the interpretative structural modeling [58] and DEMATEL [59-61] can be used for determining these structures. In this study, the experts' opinions were taken into account to develop a decision network;

Step 2: Extracting pairwise comparisons. In this step, pairwise comparison questions were asked to determine the relative significance of factors and clusters and develop an ANP decision network. The comparisons included inter-factor and inter-cluster comparisons;

Step 3: Assessing the relative importance of factors. Different online software programs are used in decision analysis to calculate the relative importance of factors. To this end, the present research utilized MATLAB software;

Step 4: Formulating a super-matrix from the weights. A super-matrix should be formulated when using the ANP method to determine the interdependence among clusters and factors. The Markov chain model and concept of super-matrix resemble each other [62]. The relative weights, calculated in Step 3, were integrated into a super-matrix based on the effect of one cluster or factor on another. Four elements were incorporated to develop a supermatrix: (1) Identifying a matrix for all alternatives, unless they influence each other; (2) determining its relationship with the final objective; (3) comparing the alternative relationships considering these factors; and (4) comparing the factors with clusters;

Step 5: Computation of stable weights from the super-matrix. To determine the stable weights of the alternatives, the power of the super-matrix, determined in Step 4, should increase to facilitate the convergence and stabilization of the weights.

\section{B.3. A gray ANP-based model}

The gray ANP-based approach is characterized by several steps: (a) constructing a decision network; (b) making pairwise comparisons; (c) assessing the relative weights of the criteria; (d) constructing a super-matrix based on the weight values; (e) evaluating the longterm weights for the super-matrix; (f) examining the priority of the supplier in different TT methods; and (g) identifying the final ranks of suppliers.

\section{Stage 3: Mathematical programming}

In this section, optimal mathematical modeling was done considering the weights of the effective criteria in the technology, TT method, and supplier selection. Their allocation to each supplier was also determined using the weights obtained from the BWM and GANP methods for comparisons. For this purpose, first, the definitions of variables and parameters in the mathematical model were provided:

$$
\begin{array}{ll}
\text { Sets } & \\
i & \text { Set of providers, } i=1,2,3, \ldots, I \\
j & \text { Set of technologies, } j=1,2,3, \ldots, J \\
k & \text { Set of TT methods, } k=1,2,3, \ldots, K
\end{array}
$$

\section{Parameters}

$\tilde{X}_{i j k} \quad$ The amount of demand from the supplier $i$ for the technology $j$ using TT method $k$

$\tilde{D} \quad$ Total product demand

$\tilde{C}_{i j k} \quad$ The capacity of the supplier $i$ for the technology $j$ using the TT method $k$

$\widetilde{T S}_{i j k} \quad$ The final score of the supplier $i$ according to the technology selection of criteria $j$ and TT method $k$

$\tilde{L}_{i j k} \quad$ The procurement time determined by the technology receiver for the technology $j$ from supplier $i$ using TT method $k$

$l_{i j k} \quad$ The required time to supply the demands for the technology $j$ by the supplier $i$ using TT method $k$ 


\begin{abstract}
$\tilde{\bar{C}}_{p} \quad$ The required level of quality defined by the technology receiver

$\tilde{C}_{i} \quad$ The quality level of the supply acquired from the supplier $i$

$\tilde{q}_{i j k} \quad$ The breakdown and maintenance rate of the acquisition process from supplier $i$ for technology $j$ using TT method $k$
\end{abstract}

$S \tilde{L} \quad$ Customer's required service level

$\tilde{S}_{i j k} \quad$ The required service level of supplier $i$ for technology $j$ using TT method $k$

$F \quad$ The desired price of the customer

$\Delta_{i j k} \quad$ The proposed price by supplier $i$ for technology $j$ using TT method $k$

$\bar{C}_{i j k} \quad$ The supply cost of supplier $i$ for technology $j$ using TT method $k$

$C_{l} \quad$ The minimum cost of technology

$\tilde{P}_{1}, \tilde{P}_{2}, \tilde{P}_{3}, \tilde{P}_{4}$ The obtained weight for each defined criterion in the target function

$Y_{i j k} \quad$ In case the demand is allocated to the supplier $i$ for technology $j$ using TT method $k$, the binary variable will be equal to 1 ; otherwise, it will be 0 .

$E_{i j k} \quad$ The degree of environmental compliance of the supplier $i$ according to technology $j$ and TT method $k$

$Z_{i} \quad$ The degree of environmental compliance demanded by the technology receiver

$\tilde{H}_{i j k} \quad$ The least commitment to the environmental issues of supplier $i$ having technology $j$ while using TT method $k$

$B_{i} \quad$ The allocated goal for supplier $i$

$d^{+} \quad$ The upper limit of deviation from the goal

$d^{-} \quad$ The lower limit of deviation from the goal

The weights obtained from BWM and GANP methods, shown by $\tilde{P}_{i}$, were considered to develop the target functions (Eqs. (19)-(22)). As a result, Eq. (23) can be obtained as:

$$
\begin{aligned}
\operatorname{Min} Z_{1} & =\sum_{i} \sum_{j} \sum_{k} \Delta_{i j k} \tilde{X}_{i j k}, \\
\operatorname{Min} Z_{2} & =\sum_{i} \sum_{j} \sum_{k} \tilde{q}_{i j k} \tilde{X}_{i j k}, \\
\operatorname{Max} Z_{3} & =\sum_{i} \sum_{j} \sum_{k} \tilde{S}_{i j k} Y_{i j k},
\end{aligned}
$$

$$
\operatorname{Max} Z_{4}=\sum_{i} \sum_{j} \sum_{k} E_{i j k} Y_{i j k}
$$

Eq. (19) represents the minimum supply cost, Eq. (20) the minimum failure, Eq. (21) the maximum level of service provided by the supplier, and Eq. (22) the maximum compliance of the supplier with environmental issues. Eqs. (19) and (20) minimize the cost and failure, and Eqs. (21) and (22) maximize theservice level and supplier's environmental compliance, respectively.

$$
\begin{aligned}
& \operatorname{Min} Z=\tilde{P}_{1} Z_{1}\left(d_{1}^{-}\right)+\tilde{P}_{2} Z_{2}\left(d_{2}^{-}\right)+\tilde{P}_{3} Z_{3}\left(d_{3}^{+}\right) \\
& +\tilde{P}_{4} Z_{4}\left(d_{4}^{+}\right), \\
& \sum_{i=1} \sum_{j=1} \sum_{k=1} T \tilde{S}_{i j k} \tilde{X}_{i j k}+d_{1}^{+}-d_{1}^{-}=B_{i} \quad \forall_{i}, \\
& \sum_{i=1} \sum_{j=1} \sum_{k=1} E_{i j k} Y_{i j k}+d_{2}^{+}-d_{2}^{-} \geq Z_{i}, \\
& \sum_{i=1} \sum_{j=1} \sum_{k=1} Z_{i} Y_{i j k}+d_{2}^{+}-d_{2}^{-} \leq \tilde{H}_{i j k}, \\
& \sum_{i=1} \sum_{j=1} \sum_{k=1} \tilde{C}_{i} Y_{i j k}+d_{3}^{+}-d_{3}^{-} \cong \bar{C}_{p} \sum_{i=1} \sum_{j=1} \sum_{k=1} Y_{i j k}, \\
& \sum_{i=1} \sum_{j=1} \sum_{k=1} \Delta_{i j k} Y_{i j k}+d_{4}^{+}-d_{4}^{-}=F \sum_{i=1} \sum_{j=1} \sum_{k=1} Y_{i j k}(28) \\
& \sum_{i=1} \sum_{j=1} \sum_{k=1} \tilde{q}_{i j k} \tilde{x}_{i j k}+d_{5}^{+}-d_{5}^{-}=0, \\
& \sum_{i=1}^{n} \sum_{j=1} \sum_{k=1} \tilde{S}_{i j k} Y_{i j k}+d_{6}^{+}-d_{6}^{-}=S L \sum_{i=1} \sum_{j=1} \sum_{k=1} Y_{i j k}, \\
& \sum_{i=1}^{n} \sum_{j=1} \sum_{k=1} \bar{C}_{i j k} Y_{i j k}+d_{7}^{+}-d_{7}^{-} \geq C_{l}, \\
& \tilde{l}_{i j k} \tilde{X}_{i j k}+d_{8}^{+}-d_{8}^{-}=L_{i j k}, \\
& \sum_{i=1}^{n} \sum_{j=1} \sum_{k=1} \tilde{X}_{i j k}=\tilde{D}_{i}, \\
& \tilde{X}_{i j k} \leq \tilde{C}_{i j k} .
\end{aligned}
$$

Eq. (23) is the target function, determining the amount of allocation to each supplier based on the defined goals (Eqs. (17)-(20)). According to the capacity of each supplier, the highest amount of allocation was attributed to each supplier to meet the four goals the technology receiver pursues.

Constraint (24) presents the final score of each 
Table 3. The weights of criteria based on the BWM.

\begin{tabular}{|c|c|c|c|c|c|c|c|c|}
\hline Row & Category & $\begin{array}{l}\text { Category } \\
\text { weight }\end{array}$ & Factor & $\begin{array}{l}\text { Factor } \\
\text { weight }\end{array}$ & $\xi^{*}$ & $\begin{array}{c}\text { Compatibility } \\
\text { level }\end{array}$ & $\begin{array}{l}\text { The final } \\
\text { weight of } \\
\text { the factor }\end{array}$ & $\begin{array}{l}\text { Final } \\
\text { rank }\end{array}$ \\
\hline 1 & \multirow{6}{*}{$\begin{array}{c}\text { Technology } \\
\text { selection } \\
(\mathrm{T})\end{array}$} & \multirow{6}{*}{0.153} & Technology & 0.157 & \multirow{6}{*}{0.157} & \multirow{6}{*}{0.0318} & 0.024 & 8 \\
\hline 2 & & & Infrastructural issues & 0.272 & & & 0.069 & 4 \\
\hline 3 & & & Foresight & 0.175 & & & 0.027 & 7 \\
\hline 4 & & & Terms and Conditions & 0.053 & & & 0.008 & 14 \\
\hline 5 & & & Risk & 0.181 & & & 0.028 & 6 \\
\hline 6 & & & Recipient organization & 0.162 & & & 0.025 & 9 \\
\hline 7 & \multirow{4}{*}{$\begin{array}{c}\text { TT method } \\
\text { selection } \\
(\mathrm{E})\end{array}$} & \multirow{4}{*}{0.587} & Guarantee of success & 0.158 & \multirow{4}{*}{0.0831} & \multirow{4}{*}{0.0164} & 0.091 & 3 \\
\hline 8 & & & Infrastructure & 0.614 & & & 0.360 & 1 \\
\hline 9 & & & Organizational affairs & 0.172 & & & 0.101 & 2 \\
\hline 10 & & & Environmental issues & 0.106 & & & 0.062 & 5 \\
\hline 11 & \multirow{5}{*}{$\begin{array}{l}\text { Supplier } \\
\text { selection } \\
\text { (G) }\end{array}$} & \multirow{5}{*}{0.062} & Recipient organization & 0.157 & \multirow{5}{*}{0} & \multirow{5}{*}{0} & 0.009 & 13 \\
\hline 12 & & & Terms and Conditions & 0.166 & & & 0.0103 & 12 \\
\hline 13 & & & Risk & 0.277 & & & 0.017 & 11 \\
\hline 14 & & & Foresight & 0.085 & & & 0.005 & 15 \\
\hline 15 & & & Product's state & 0.315 & & & 0.019 & 10 \\
\hline
\end{tabular}

supplier. The higher the supplier's score is, the more demand is allocated to the supplier. Constraints (25) and (26) indicate the supplier's environmental compliance and minimum supplier allocation, respectively. These relations represent the highest to the lowest environmental compliance of suppliers as well as the allocated amount to each supplier. Constraint (27) guarantees the minimum quality level required to select a supplier. Constraint (28) determines the price set by the supplier to supply the demand and selects the supplier who offers the lowest price. Constraint (29) indicates the amount of technology failure of each supplier. In other words, it chooses the supplier with the lowest failure rate.

Due to the increasing importance of service satisfaction, Constraint (30) represents the level of satisfaction with the supplier's services. Constraint (31) shows the fixed price of technology (e.g., technology, transportation, and side costs) for each supplier. It is generally desirable to pay less for the desired technology. Constraint (32) shows the supplier's delivery time. Generally, time reduction is preferable for the receiving company. In other words, the shorter the delivery time, the higher the supplier's allocation. Constraint (33) shows that selecting and assigning orders in a given period of time must be adequate, considering the technology receiver's demand. Constraint (34) considers each supplier's ability into account and ensures that orders do not exceed the capacity of the supplier.

\section{Findings}

As shown in the model presented in Figure 1, the results were analyzed based on the finalized criteria obtained from assessing the documents and conducting open interviews with managers and experts of the drill goods supply and purchasing department of Iranian Central Oil Fields Company. In this regard, the pairwise comparison questionnaires were first developed and then distributed among the experts. Calculations were performed based on Eqs. (1)-(7). Table 3 lists the weighing results based on the BWM.

According to Table 3, while "infrastructural issues" can be regarded as the most important criteria in technology selection, the "infrastructures" and "organizational affairs" are the most important criteria in the TT method selection. On the contrary, the product's state is the most important criterion in the supplier selection. A general look at all 15 criteria reveals that the criterion of "infrastructural issues" is the first priority, followed by "organizational affairs" and "guarantee of success". Given that the amount of $\xi^{*}$ calculated for the supplier category is zero, the obtained weights are completely reliable and consistent. The reliability and consistency of the TT category and technology selection are also obtained as $\xi^{*}=0.0831$ and 0.157 , respectively. Table 4 lists the weight values of the criteria using GANP.

According to Table 4, the most important cri- 
Table 4. The weights of criteria based on the GANP method.

\begin{tabular}{lcc}
\hline \multicolumn{1}{c}{ Factor } & $\begin{array}{c}\text { The final } \\
\text { weight of } \\
\text { the factor }\end{array}$ & Rank \\
\hline Technology & 0.122 & 2 \\
Infrastructural issues & 0.077 & 7 \\
Foresight & 0.058 & 9 \\
Terms and Conditions & 0.077 & 7 \\
Risk & 0.096 & 6 \\
Recipient organization & 0.071 & 8 \\
Guarantee of success & 0.146 & 3 \\
Infrastructure & 0.1 & 5 \\
Organizational affairs & 0.146 & 1 \\
Environmental issues & 0.108 & 4 \\
\hline
\end{tabular}

teria in the technology selection and transfer are the "organizational affairs" and "technology", respectively, and the least important criterion is "foresight". Given that listing the weights of all constraining factors (e.g., cost, minimum failure, maximum service level, environmental compliance, technology supplier, and TT method) requires a prolonged single table, Table A.1, presented in the Appendix, shows the weights obtained from the BWM and GANP methods in APPENDIX A. It should be noted that the top five suppliers were selected after determining the values and ranks of 13 primary suppliers according to the assessment criteria. In addition, followed by weighing the criteria and ranking the TT methods based on the decisionmaking techniques, five transfer methods and three technologies were selected.

At this stage, once the weights were calculated using the GAMS 24 software, the mathematical model was solved. In this respect, the GAMS 24 software was used to select the best supplier(s) and assign the optimal allocation to each supplier. Table 5 presents the results of problem-solving based on the defined criteria. The lowest cost of supply was attributed to
Table 6. Demand allocation to each supplier.

\begin{tabular}{cccc}
\hline \multirow{2}{*}{ Supplier } & \multicolumn{3}{c}{ Technology } \\
\cline { 2 - 4 } & $\begin{array}{c}\text { Roller cone } \\
\text { bits }\end{array}$ & $\begin{array}{c}\text { Polycrystalline } \\
\text { diamond compacts }\end{array}$ & $\begin{array}{c}\text { Core } \\
\text { Bits }\end{array}$ \\
\hline 1 & 0 & 0 & 0 \\
2 & 1558 & 1828 & 1567 \\
3 & 0 & 0 & 0 \\
4 & 1768 & 1836 & 1954 \\
5 & 3215 & 2453 & 2864 \\
Total & 6541 & 6117 & 6385 \\
\hline
\end{tabular}

Supplier 5 with 293 monetary units, followed by Suppliers 2 and 4 . Supplier 5 was selected as the optimal one, considering the negative impact of increased costs. However, the GANP method selected Supplier 2 with 308 monetary units. According to the results from the BWM, followed by integrating the other three factors besides the "supply cost", Supplier 5 was again selected as the first choice for optimal allocation and supply of demands, followed by Suppliers 2 and 4, in order. Table 6 shows the optimal allocation to each supplier based on the results of problem-solving in GAMS 24 .

As shown in Table 6, the highest demand allocation is attributed to Supplier 5 (3215 roller cone bits, 2453 polycrystalline diamond compacts, and 2864 core bits), which is in line with the results of BWM, as shown in Table 5. Therefore, Supplier 5 was found to be superior to the other two suppliers. In addition, Suppliers 2, 4, and 5 supplied all demands for bits.

Table 7 presents the optimal values of goals, considering the weights obtained from each method. This table indicates the optimal range of allocation for each product. It should be noted that the optimal values in this table were obtained according to the weights measured through the BWM and GANP methods. The deviations from the optimal values based on additional allocations are presented in Table 8.

\section{Conclusion}

Selection of appropriate technology, Technology Transfer (TT) method, and optimal supplier has a significant

Table 5. The optimal values for each supplier according to two different decision-making methods.

\begin{tabular}{|c|c|c|c|c|c|c|c|c|}
\hline \multirow{3}{*}{$\begin{array}{c}\text { Supplier } \\
\text { (s) }\end{array}$} & \multicolumn{4}{|c|}{ BWM } & \multicolumn{4}{|c|}{ GANP } \\
\hline & $\begin{array}{c}\text { Cost (in } \\
\text { thousands } \\
\text { of dollars) }\end{array}$ & $\begin{array}{l}\text { Minimum } \\
\text { failure }\end{array}$ & $\begin{array}{l}\text { Compliance of } \\
\text { supplier with } \\
\text { environmental } \\
\text { issues }\end{array}$ & $\begin{array}{c}\text { Maximum } \\
\text { service } \\
\text { level }\end{array}$ & $\begin{array}{c}\text { Cost (in } \\
\text { thousands } \\
\text { of dollars) }\end{array}$ & $\begin{array}{l}\text { Minimum } \\
\text { failure }\end{array}$ & $\begin{array}{l}\text { Compliance of } \\
\text { supplier with } \\
\text { environmental } \\
\text { issues }\end{array}$ & $\begin{array}{l}\text { Maximum } \\
\text { service } \\
\text { level }\end{array}$ \\
\hline & Minimum & Minimum & Maximum & Maximum & Minimum & Minimum & Maximum & Maximum \\
\hline 1 & 354 & 0.028 & 0.82 & 0.92 & 363 & 0.025 & 0.82 & 0.90 \\
\hline 2 & 300 & 0.002 & 0.95 & 0.96 & 308 & 0.005 & 0.93 & 0.92 \\
\hline 3 & 371 & 0.012 & 0.63 & 0.90 & 373 & 0.014 & 0.73 & 0.87 \\
\hline 4 & 311 & 0.004 & 0.95 & 0.95 & 317 & 0.007 & 0.93 & 0.90 \\
\hline 5 & 293 & 0.001 & 0.95 & 0.96 & 318 & 0.003 & 0.90 & 0.91 \\
\hline
\end{tabular}


Table 7. The optimal values and sensitivity analysis of each product.

\begin{tabular}{lcccccccc}
\hline \multirow{2}{*}{ Technology } & \multicolumn{3}{c}{ Via BWM weights } & & \multicolumn{2}{c}{ Via GANP weights } \\
\cline { 2 - 3 } \multicolumn{1}{c}{$\begin{array}{c}\text { Upper } \\
\text { bound }\end{array}$} & Amount & $\begin{array}{c}\text { Lower } \\
\text { bound }\end{array}$ & & $\begin{array}{c}\text { Upper } \\
\text { bound }\end{array}$ & Amount & $\begin{array}{c}\text { Lower } \\
\text { bound }\end{array}$ \\
\hline Roller cone bits & 6562 & 6541 & 6538 & & 6586 & 6541 & 6527 \\
Polycrystalline diamond compacts & 6120 & 6117 & 6112 & & 6175 & 6117 & 6109 \\
Core bits & 6391 & 6385 & 6380 & & 6411 & 6385 & 6373 \\
\hline
\end{tabular}

Table 8. Deviations from the optimal values.

\begin{tabular}{clcc}
\hline Row & \multicolumn{1}{c}{ Goals } & $\begin{array}{c}\text { Negative } \\
\text { deviation }\end{array}$ & $\begin{array}{c}\text { Positive } \\
\text { deviation }\end{array}$ \\
\hline 1 & Cost (in thousands of dollars) & 304 & 0 \\
2 & Minimum failure & 0.002 & 0 \\
3 & Environmental compliance & 0 & 0.93 \\
4 & Maximum service level & 0 & 0.95 \\
\hline
\end{tabular}

effect on organizations through reduction of costs and environmental issues, efficiency enhancement, organizational and individual capability promotion, risk control, and proper planning for the optimal use of time and resources. In this regard, the Goal Programming (GP) method, along with the Best-WorstMethod (BWM), was used in this study to select the best suppliers and allocate the optimal demands. In addition, the Gray Analytical Network Process (GANP) decision-making method was used to compare the results with those obtained from integrating the BWM method into the GP. The main objectives of the GP in this study can be summarized as follows: 1) reduction of the TT cost; 2) enhancement of quality; 3 ) promotion of service level; and 4) reduction of environmental damages (Eqs. (17) to (20)). This study primarily aimed to rank the criteria for technology and TT method selection. According to Table 3, the "infrastructural issues" criterion was the most important criterion in the BWM method. Therefore, special attention must be paid to issues such as the required hardware and software for product/technology transfer, organizational and cultural adaptability, and required internal and international laws. According to the results of the GANP method presented in Table 4, the "organizational affairs" criterion was the most important one. Despite the importance of this criterion in the TT process, even when considering all of its sub-criteria and selecting the most compatible technology, the TT process cannot be successful, unless the infrastructures necessary for technology transfer and utilization are available. From this point of view, the BWM method, as expected, yielded more accurate results than the GANP method. The selection of suppliers was done depending on the weights obtained from the BWM and GANP methods used in the mathematical programming model. Finally, the demands were supplied using GP. The results of problem-solving in the mathematical model indicated the superiority of BWM to other methods. Future studies can explore other combinations such as Interval-Valued FuzzyRough Number (IVFRN)-BWM used along with GP.

\section{References}

1. Zack, M.H. "Developing a knowledge strategy", Calif. Manage. Rev., 41(3), pp. 125-145 (1999).

2. García-Vega, M. and Huergo, E. "Trust and technology transfers", J. Econ. Behav. Organ., 142, pp. 92-104 (2017).

3. Motohashi, K. and Yuan, Y. "Productivity impact of technology spillover from multinationals to local firms: Comparing China's automobile and electronics industries", Res. Policy, 39(6), pp. 790-798 (2010).

4. Akhundzadeh, M. and Shirazi, B. "Technology selection and evaluation in Iran's pulp and paper industry using 2-filterd fuzzy decision making method", $J$. Clean. Prod., 142, pp. 3028-3043 (2017).

5. Danquah, M. "Technology transfer, adoption of technology and the efficiency of nations: Empirical evidence from sub Saharan Africa", Technol. Forecast. Soc. Change, 131 (December 2016), pp. 175-182 (2018).

DOI: https://doi.org/10.1016/j.techfore.2017.12.007

6. Klintenberg, P., Wallin, F., and Azimoh, L.C. "Successful technology transfer: What does it take?", Appl. Energy, 130, p. 807 (2014).

7. Jafarnezhad, A., Asgharizadeh, E., and Asemian, G. "Priority of technology transfer methods in oil drilling industry by using analysis network process (ANP)", Int. J. Learn. Dev., 3(5), pp. 15-25 (2013).

8. Shen, Y.C., Lin, G.T.R., and Tzeng, G.H. "Combined DEMATEL techniques with novel MCDM for the organic light emitting diode technology selection", Expert Syst. Appl., 38(3), pp. 1468-1481 (2011).

9. Abdullah, L. and Rahman, N.A.A. "Analytic network process for developing relative weight of wastewater treatment technology selection", Mod. Appl. Sci., 11(5), pp. 64-72 (2017).

10. Aliakbari Nouri, F., Khalili Esbouei, S., and Antucheviciene, J. "A hybrid MCDM approach based on fuzzy ANP and fuzzy TOPSIS for technology selection", Informatica, 26(3), pp. 369-388 (2015). 
11. Lee, A.H.I., Wang, W.M., and Lin, T.Y. "An evaluation framework for technology transfer of new equipment in high technology industry", Technol. Forecast. Soc. Change, 77(1), pp. 135-150 (2010).

12. Dou, Y., Zhu, Q., and Sarkis, J. "Evaluating green supplier development programs with a grey-analytical network process-based methodology", Eur. J. Oper. Res., 233(2), pp. 420-431 (2014).

13. Tuzkaya, U. and Yolver, E. "R\&D project selection by integrated grey analytic network process and grey relational analysis: an implementation for home appliances company", J. Aeronaut. Sp. Technol., 8(2), pp. 35-41 (2015).

14. Lu, C., You, J.X., Liu, H.C., et al. "Health-care waste treatment technology selection using the interval 2tuple induced TOPSIS method", Int. J. Environ. Res. Public Health, 13(6), p. 562 (2016).

15. Iç, Y.T. "An experimental design approach using TOPSIS method for the selection of computerintegrated manufacturing technologies", Robot. Comput. Integr. Manuf., 28(2), pp. 245-256 (2012).

16. Taghavifard, M., Rostami, M., Mahdi, S., et al. "A hierarchical fuzzy topsis model for evaluating technology transfer of medical equipment", Int. J. Acad. Res., 3(3), pp. 511-520 (2011).

17. Sharawat, K. and Dubey, S.K. "Diet recommendation for diabetic patients using MCDM approach", in $A d$ vances in Intelligent Systems and Computing, Springer Verlag, 624, pp. 239-246 (2018).

18. Kumar, S., Luthra, S., and Haleem, A. "Benchmarking supply chains by analyzing technology transfer critical barriers using AHP approach", Benchmarking an Int. J., 22(4), pp. 538-558 (2015).

19. Hu, W., Liu, G., and Tu, Y. "Wastewater treatment evaluation for enterprises based on fuzzy-AHP comprehensive evaluation: A case study in industrial park in Taihu Basin, China", Springerplus, 5(1), pp. 1-15 (2016).

20. Farshidi, S., Jansen, S., de Jong, R., et al. "A decision support system for software technology selection", $J$. Decis. Syst., 27(sup1), pp. 98-110 (2018).

21. Mokhtarzadeh, N., Mahdiraji, H., Beheshti, M., et al. "A novel hybrid approach for technology selection in the information technology industry", Technologies, 6(1), p. 34 (2018).

22. Rahimi, F., Goli, A., and Rezaee, R. "Hospital location-allocation in Shiraz using geographical information system (GIS)", Shiraz E Med. J., 18(8), pp. 1-8 (2017).

23. Amirghodsi, S., Bonyadi Naeini, A., and Roozbehani, B. "An integrated shannon-PAF method on gray numbers to rank technology transfer strategies", EMJ Eng. Manag. J., 32(3), pp. 186-207 (2020).

24. Sahin, B. and Yip, T.L. "Shipping technology selection for dynamic capability based on improved Gaussian fuzzy AHP model", Ocean Eng., 136, pp. 233-242 (2017).
25. Mardani, A., Zavadskas, E.K., Streimikiene, D., et al. "A comprehensive review of data envelopment analysis (DEA) approach in energy efficiency", Renew. Sustain. Energy Rev., 70, pp. 1298-1322 (2017).

26. Goker, N. and Karsak, E.E. "An improved common weight DEA-based methodology for manufacturing technology selection", in Lecture Notes in Engineering and Computer Science, Newswood Limited, 2226, pp. 864-869 (2016).

27. Ren, J. "Technology selection for ballast water treatment by multi-stakeholders: A multi-attribute decision analysis approach based on the combined weights and extension theory", Chemosphere, 191, pp. 747-760 (2018).

28. Van de Kaa, G., Kamp, L., and Rezaei, J. "Selection of biomass thermochemical conversion technology in the Netherlands: A best worst method approach", $J$. Clean. Prod., 166, pp. 32-39 (2017).

29. Rezaei, J., Kothadiya, O., Tavasszy, L., et al. "Quality assessment of airline baggage handling systems using SERVQUAL and BWM", Tour. Manag., 66, pp. 85-93 (2018).

30. Rezaei, J., Nispeling, T., Sarkis, J., et al. "A supplier selection life cycle approach integrating traditional and environmental criteria using the best worst method", J. Clean. Prod., 135, pp. 577-588 (2016).

31. Setyono, R.P. and Sarno, R. "Comparative method of Moora and CoprAs based on weighting of the best worst method in supplier selection at $\mathrm{ABC}$ mining companies in Indonesia", in 2019 International Conference on Information and Communications Technology, ICOIACT 2019, Institute of Electrical and Electronics Engineers Inc., pp. 354-359 (2019).

32. Xu, D., Li, W., Ren, X., et al. "Technology selection for sustainable hydrogen production: A multi-criteria assessment framework under uncertainties based on the combined weights and interval best-worst projection method", Int. J. Hydrogen Energy, 45(59), pp. 3439634411 (2020).

DOI: https://doi.org/10.1016/j.ijhydene.2019.09.030

33. Jafarzadeh Ghoushchi, S., Khazaeili, M., Amini, A., et al. "Multi-criteria sustainable supplier selection using piecewise linear value function and fuzzy best-worst method", J. Intell. Fuzzy Syst., 37(2), pp. 2309-2325 (2019).

34. Hendalianpour, A., Fakhrabadi, M., Zhang, X., et al. "Hybrid model of IVFRN-BWM and robust goal programming in agile and flexible supply chain, a case study: Automobile industry", IEEE Access, 7, pp. 71481-71492 (2019).

35. Lee, J.W. and Kim, S.H. "Using analytic network process and goal programming for interdependent information system project selection", Comput. Oper. Res., 27(4), pp. 367-382 (2000).

36. Yurdakul, M. "Selection of computer-integrated manufacturing technologies using a combined analytic hierarchy process and goal programming model", Robot. Comput. Integr. Manuf., 20(4), pp. 329-340 (2004). 
37. Feng, B., Fan, Z.P., and Li, Y. "A decision method for supplier selection in multi-service outsourcing", Int. J. Prod. Econ., 132(2), pp. 240-250 (2011).

38. Kannan, D., Khodaverdi, R., Olfat, L., et al. "Integrated fuzzy multi criteria decision making method and multiobjective programming approach for supplier selection and order allocation in a green supply chain", J. Clean. Prod., 47, pp. 355-367 (2013).

39. Li, D.F. and Wan, S.P. "Fuzzy linear programming approach to multiattribute decision making with multiple types of attribute values and incomplete weight information", Appl. Soft Comput. J., 13(11), pp. 43334348 (2013).

40. Hamurcu, M. and Eren, T. "A hybrid approach of analytic hierarchy process-topsis and goal programming for electric automobile selection", in In The 2018 International Conference of the African Federation of Operational Research Societies (AFROS 2018). (https://www.mendeley.com/catalogue/d7a57562-0c75-3fd5-8ba7-ca025faac965/, 2018), p. 2.

41. Lin, R., Man, Y., Lee, C.K.M., et al. "Sustainability prioritization framework of biorefinery: A novel multi-criteria decision-making model under uncertainty based on an improved interval goal programming method", J. Clean. Prod., 251, p. 119729 (2020).

42. Vahidi, F., Torabi, S.A., and Ramezankhani, M.J. "Sustainable supplier selection and order allocation under operational and disruption risks", J. Clean. Prod., 174, pp. 1351-1365 (2018).

43. Sarkar, S., Pratihar, D.K., and Sarkar, B. "An integrated fuzzy multiple criteria supplier selection approach and its application in a welding company", J. Manuf. Syst., 46, pp. 163-178 (2018).

44. Hendalianpour, A., Fakhrabadi, M., Sangari, M.S., et al. "A combined benders decomposition and lagrangian relaxation algorithm for optimizing a multi-product, multi-level omni-channel distribution system", Sci. Iran., Transactions on Industrial Engineering (E), 29(1), pp. 355-371 (2022).

DOI: https://dx.doi.org/10.24200/sci.2020.53644.3349

45. Mazdeh, M.M., Ali Shafia, M., Bandarian, R., et al. "An ISM approach for analyzing the factors in technology transfer", Decis. Sci. Lett., 4(3), pp. 335348 (2015).

46. Kharat, M.G., Raut, R.D., Kamble, S.S., et al. "The application of Delphi and AHP method in environmentally conscious solid waste treatment and disposal technology selection", Manag. Environ. Qual. an Int. J., 27(4), pp. 427-440 (2016).

47. Montazeri, M.M. and Najjartabar-Bisheh, M. "Optimizing technology selection for power smart grid systems: A case study of Iran power distribution industry (IPDI)", Technol. Econ. Smart Grids Sustain. Energy, 2(1), p. 6 (2017).

48. Rezaei, J. "Best-worst multi-criteria decision-making method", Omega, United Kingdom, 53, pp. 49-57 (2015).
49. Pamučar, D., Petrović, I., and Ćirović, G. "Modification of the best-worst and MABAC methods: A novel approach based on interval-valued fuzzy-rough numbers", Expert Syst. Appl., 91, pp. 89-106 (2018).

50. Wan Ahmad, W.N.K., Rezaei, J., Sadaghiani, S., et al. "Evaluation of the external forces affecting the sustainability of oil and gas supply chain using best worst method", J. Clean. Prod., 153, pp. 242-252 (2017).

51. Rezaei, J. "Best-worst multi-criteria decision-making method: Some properties and a linear model", Omega, United Kingdom, 64, pp. 126-130 (2016).

52. Razmi, J., Sangari, M.S., and Ghodsi, R. "Developing a practical framework for ERP readiness assessment using fuzzy analytic network process", Adv. Eng. Softw., 40(11), pp. 1168-1178 (2009).

53. Sarkis, J. and Sundarraj, R.P. "Factors for strategic evaluation of enterprise information technologies", Int. J. Phys. Distrib. Logist. Manag., 30, pp. 196-220 (2000).

54. Lin, J.J. and Wei, Y.H. "Assessing area-wide bikeability: A grey analytic network process", Transp. Res. Part A Policy Pract., 113, pp. 381-396 (2018).

55. Deng, J.L. "Control problems of grey systems", Syst. Control Lett., 1(5), pp. 288-294 (1982).

56. Opricovic, S. and Tzeng, G.H. "Defuzzification within a multicriteria decision model", Int. J. Uncertainty, Fuzziness Knowledge-Based Syst., 11(5), pp. 635-652 (2003).

57. Deng, J.L. "Introduction to grey system theory", $J$. grey Syst., 1(1), pp. 1-24 (1989).

58. Sarkis, J., Hasan, M.A., and Shankar, R. "Evaluating environmentally conscious manufacturing barriers with interpretive structural modeling", in Environmentally Conscious Manufacturing VI, SPIE, 6385, p. 638508 (2006).

59. Fontela, E. and Gabus, A. "The DEMATEL observer", DEMATEL 1976 Report (1976).

60. Gabus, A. and Fontela, E. "World problems, an invitation to further thought within the framework of DEMATEL", Battelle Geneva Res. Cent., pp. 1-12 (1974).

61. Amirghodsi, S., Bonyadi Naeini, A., and Makui, A. "An integrated delphi-DEMATEL-ELECTRE method on gray numbers to rank technology providers", IEEE Trans. Eng. Manag., 69(4), pp. 1348-1364 (2022). DOI: https://doi.org/10.1109/TEM.2020.2980127

62. Saaty, T., Decision Making with Dependence and Feedback: The Analytic Network Process, RWS Publications (1996).

\section{Appendix}

The weights obtained from the BWM and GANP methods are shown in Table A.1. 
Table A.1. The weights of the constraining factors in the mathematical model for each technology, TT method, and supplier.

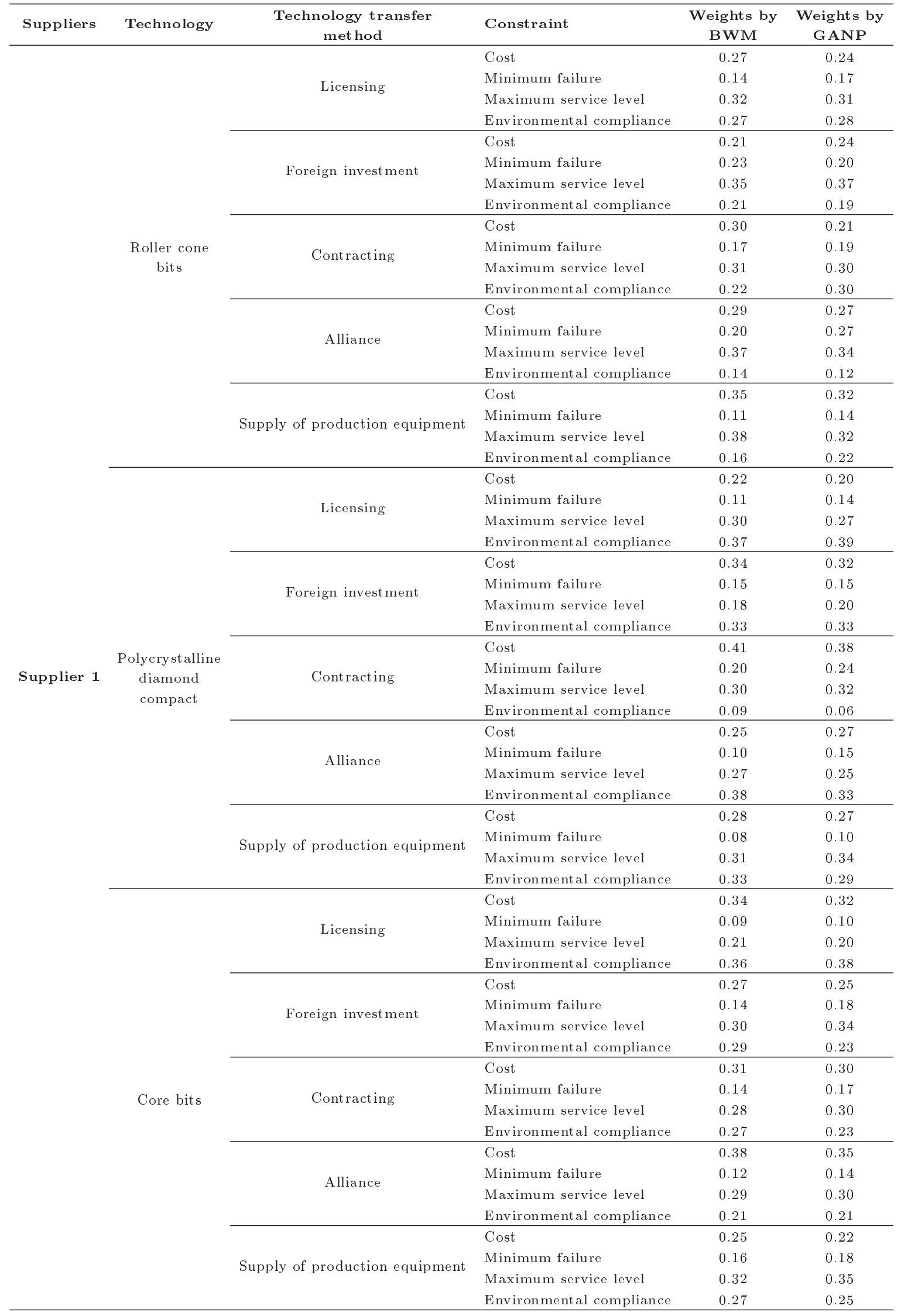


Table A.1. The weights of the constraining factors in the mathematical model for each technology, TT method, and supplier (continued).

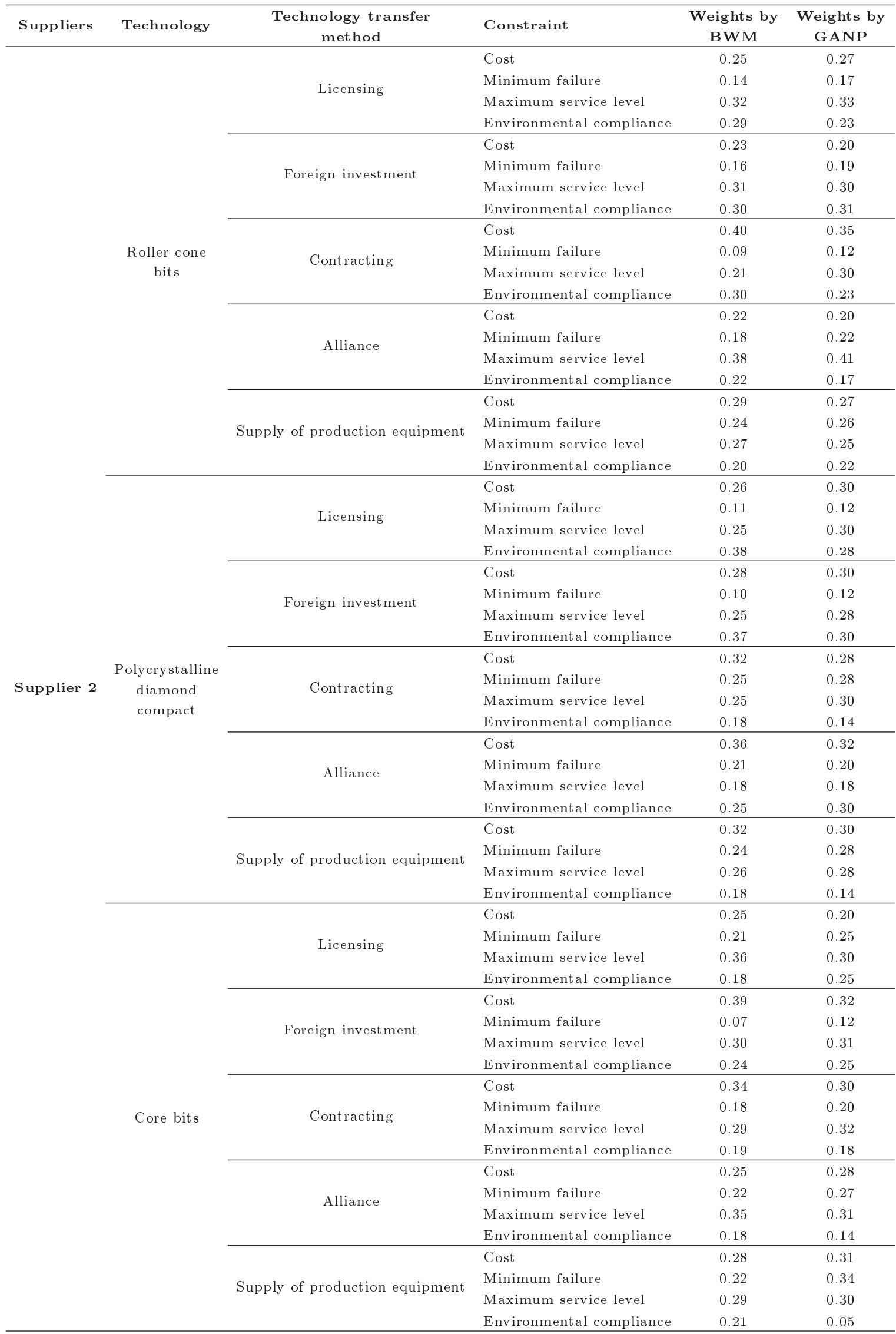


Table A.1. The weights of the constraining factors in the mathematical model for each technology, TT method, and supplier (continued).

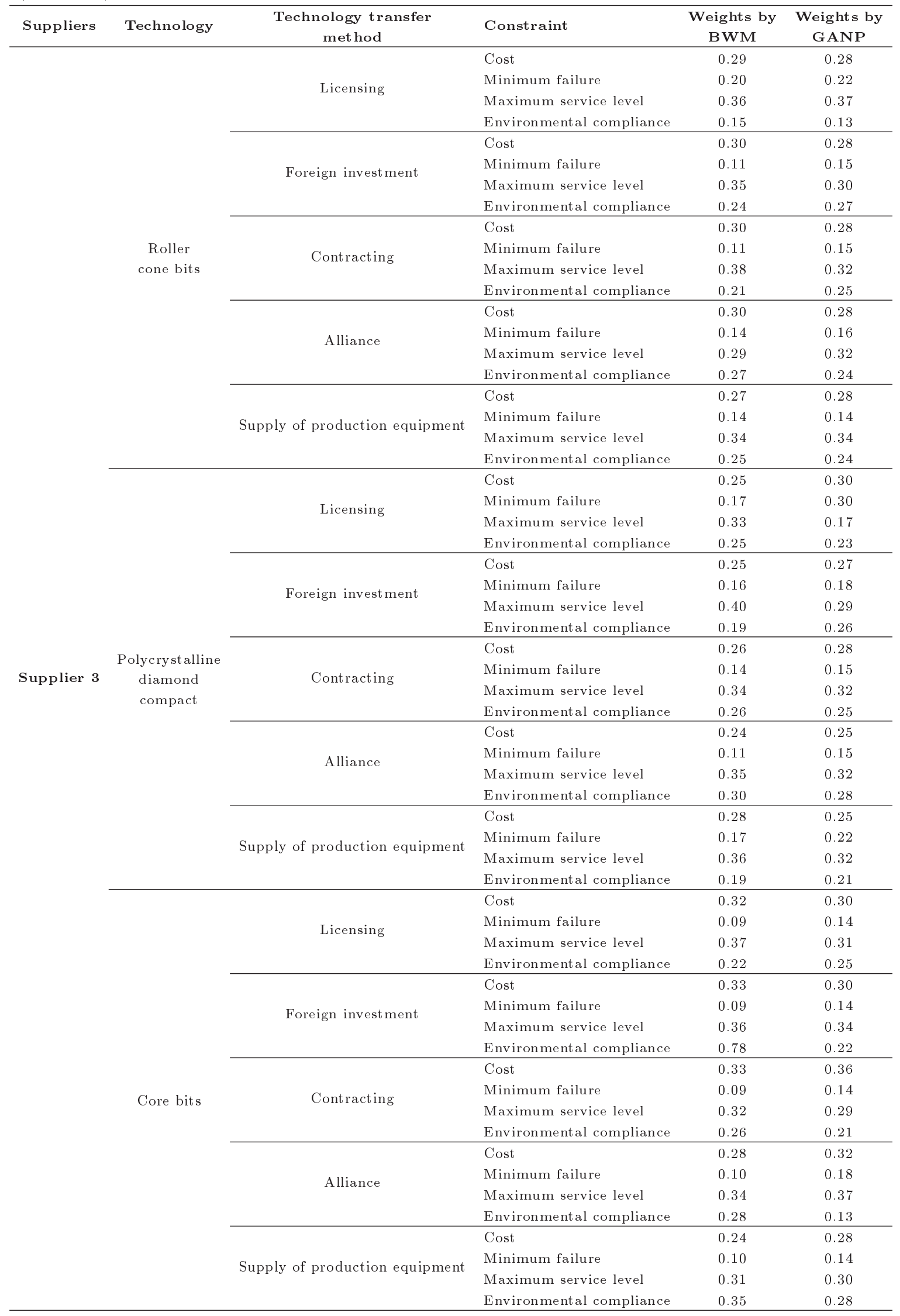


Table A.1. The weights of the constraining factors in the mathematical model for each technology, TT method, and supplier (continued).

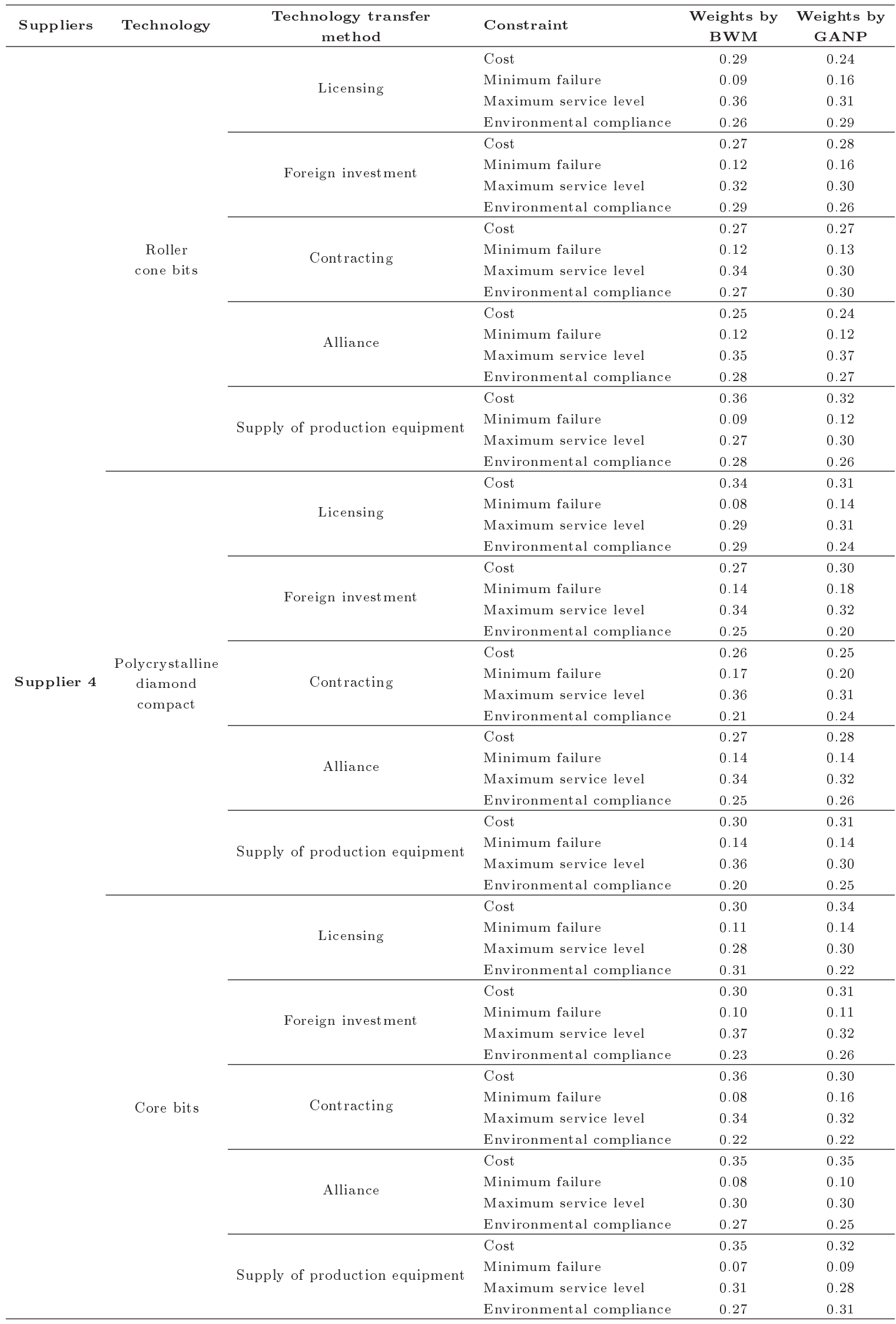


Table A.1. The weights of the constraining factors in the mathematical model for each technology, TT method, and supplier (continued).

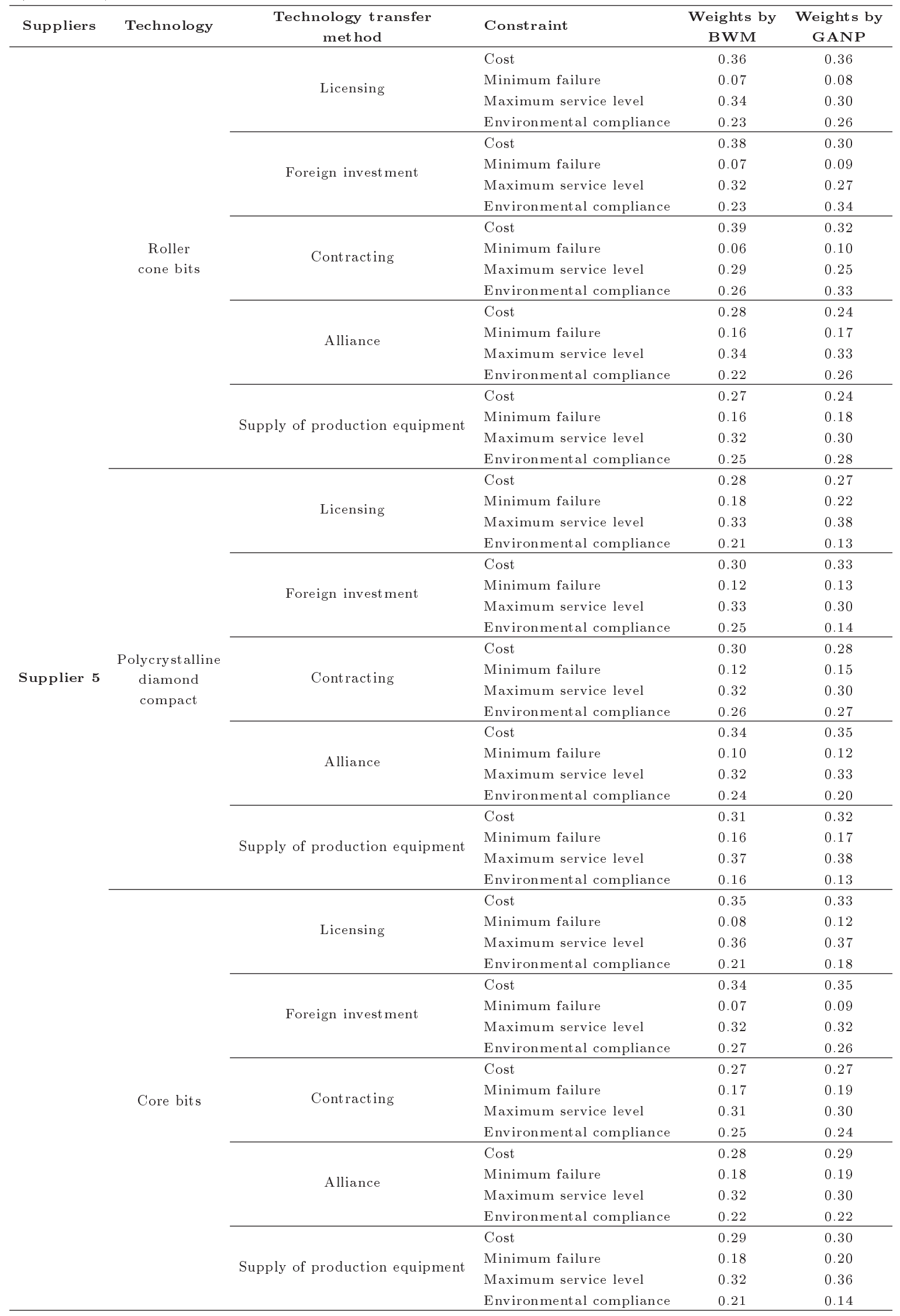




\section{Biographies}

Sirous Amirghodsi received his BSc degree in Civil Engineering from Khajeh Nasir Toosi University, Tehran, Iran in 1995, and MBA degree in Executive Master of Business Administration from Iran University of Science and Technology (IUST), Tehran in 2014. He recently received his $\mathrm{PhD}$ degree in Technology Management with the Progress Engineering Department, IUST. He was recognized as one of the Premier Researchers in 2019. His research interests include technology transfer, multi-criteria decision making, and knowledge management of engineering projects.

Ali Bonyadi Naeini is a faculty member of the Progress Engineering Department of Iran University of Science and Technology. He has taught several courses in fields of marketing management, neuromarketing, and management of technology and innovation. He has also presented several conference papers and scholarly journal papers on quantitative decision-making techniques such as DEA, DEMATEL, and ISM and authored two books in the field of neuromarketing.

Ahmad Makui received his BA, MBA, and PhD degrees in Industrial Engineering from Iran University of Science and Technology (IUST), Tehran, Iran, in 1985, 1991, and 1994, respectively. He is currently a Professor at the Department of Industrial Engineering, Iran University of Science and Technology, Tehran, Iran. He published four books in the field of operation research, production planning, and MCDM. His research interests include operations research, production planning, multi-criteria decision making, and technology transfer. Mr. Makui is the Editor-in-Chief of the Journal of Industrial and Systems Engineering. 